\title{
Addition of Manas barley chromosome arms to the hexaploid wheat genome
}

\author{
Edina Türkösi, András Cseh, Éva Darkó and Márta Molnár-Láng*
}

\begin{abstract}
Background: Cultivated barley belongs to the tertiary genepool of hexaploid wheat. Genes of interest can be transferred from barley into wheat through wide hybridization. The application of wheat-barley introgression lines could provide an excellent tool for the transfer of earliness, favourable amino acid composition, biotic stress resistance, abiotic stress tolerance, or good tillering ability into wheat.

Results: A set of 10 wheat-barley ditelosomic addition lines $(2 \mathrm{HS}, 2 \mathrm{HL}, 3 \mathrm{HS}, 3 \mathrm{HL}, 4 \mathrm{HS}, 4 \mathrm{HL}, 6 \mathrm{HS}, 6 \mathrm{HL}, 7 \mathrm{HS}$ and $7 \mathrm{HL})$ was developed from the progenies of an Asakaze/Manas wheat-barley hybrid produced in Martonvásár, Hungary. The addition lines were selected from self-fertilized plants of the $\mathrm{BC}_{2} \mathrm{~F}_{2}-\mathrm{BC}_{2} \mathrm{~F}_{4}$ generations using genomic in situ hybridization (GISH) and were identified by fluorescence in situ hybridization (FISH) with repetitive DNA probes $[$ HvT01, (GAA) 7 and centromere-specific (AGGGAG) 4 probes]. The cytogenetic identification was confirmed using barley arm-specific SSR and STS markers. The ditelosomic additions were propagated in the phytotron and in the field, and morphological parameters (plant height, tillering, length of the main spike, number of seeds/spike and seeds/plant, and spike characteristics) were described. In addition, the salt stress response of the ditelosomic additions was determined.

Conclusions: The six-rowed winter barley cultivar Manas is much better adapted to Central European environmental conditions than the two-rowed spring barley Betzes previously used in wheat-barley crosses. The production of wheat-barley ditelosomic addition lines has a wide range of applications both for breeding (transfer of useful genes to the recipient species) and for basic research (mapping of barley genes, genetic and evolutionary studies and heterologous expression of barley genes in the wheat background).
\end{abstract}

Keywords: Wheat-barley ditelosomic addition lines, Genomic in situ hybridization, Fluorescence in situ hybridization, SSR and STS markers, Morphological parameters, Salt stress response

\section{Background}

Attempts to hybridize wheat with barley were begun more than 100 years ago [1], but the first authentic hybrid was obtained much later by the Danish scientist Kruse [2], who used barley as the female parent [3-5]. The production of the reciprocal hybrid (with wheat as the female parent and barley as the male parent) is more difficult, but this kind of combination is now in the focus of research in this field because of the pistilloidy and male sterility observed in barley $\times$ wheat hybrids [6] The development of the first wheat $\times$ barley hybrids was followed by the production of wheat-barley disomic addition lines $(2 \mathrm{H}, 3 \mathrm{H}, 4 \mathrm{H}, 5 \mathrm{H}, 6 \mathrm{H}$ and $7 \mathrm{H})$, the first of

\footnotetext{
* Correspondence: molnar.marta@agrar.mta.hu

Agricultural Institute, Centre for Agricultural Research, Hungarian Academy of Sciences, H-2462 Martonvásár P.O. Box 19 Hungary
}

which arose from crosses between Chinese Spring wheat and the spring barley Betzes [7]. The success of wheat $x$ barley crosses is very dependent on the genotypes used. Previous experience demonstrated that wheat cultivars originating from the Far East have better crossability with related species. Several barley cultivars (Betzes, Igri, Manas and Osnova) were used in wheat-barley crosses in Martonvásár [8]. The Ukrainian six-rowed barley Manas has many useful agronomic characters (e.g. good winter hardiness, abiotic stress tolerance and yield ability) and is well adapted to Central European conditions [9].

The first and as yet only near complete set of hexaploid wheat-barley ditelosomic addition lines was produced by Islam in the 1980's using a set of monosomic additions of Betzes barley $(2 \mathrm{n}=2 \times=14 ; \mathrm{HH})$ chromosomes to hexaploid Chinese Spring wheat $(2 n=6 x=42$; 
AABBDD) [10]. Only 12 of the 14 possible ditelosomic addition lines could be developed, as the monosomic addition involving chromosome $1 \mathrm{H}$ was self-sterile, due to the presence of the $S h w$ sterility gene on the long arm of this chromosome [4]. A ditelosomic addition line involving barley chromosome $1 \mathrm{HS}$ was developed later [10]. The wheat-barley chromosome and chromosome arm addition lines are used for assigning genes to chromosomes and chromosome arms and for the characterization of the expression pattern of barley genes in the wheat genetic background. Wheat-barley hybrids can be used for studying the homoeologous relationship between wheat and barley genomes at chromosome level [11, 12]. The barley resistance genes can also be effective in the genetic background of wheat [3], at the same time wheat-barley introgression lines could be an excellent tool for the tranfer of earliness, favourable amino acid composition, biotic stress resistance, salt and drought tolerance, or good tillering ability from barley into wheat [5]. Wheat-barley ditelosomic addition lines, on the other hand, can act as bridging materials for generating wheat-barley translocations, which are more stable than aneuploids.

The aim of this work was to select fertile, genetically stable, wheat-barley ditelosomic addition lines from backcrossed progenies of the Asakaze/Manas wheatbarley hybrid produced earlier in Martonvásár [13, 14]. Barley chromosomes were detected in the wheat background using genomic in situ hybridization (GISH), and identified with fluorescence in situ hybridization (FISH) and molecular (SSR and STS) markers specific for barley chromosome arms. The morphological characters, yield components and salt stress response of the ten lines were also investigated.

\section{Methods}

\section{Plant material}

The Japanese facultative wheat Asakaze was used as female parent and the Ukrainian six-rowed winter barley Manas as pollinator to produce a wheat-barley hybrid. The wheat cv. Asakaze and the barley cv. Manas were provided by the Martonvasar Cereal Gene Bank. The hybrid embryo was dissected three weeks after pollination and raised in embryo culture [13]. The hybrid plant had good viability and developed several tillers. As the hybrid was sterile, it was multiplied from young inflorescences in tissue culture. Spikes from 354 regenerant hybrids were pollinated with the wheat cultivars Asakaze, Mv9 $\mathrm{kr} 1$ and Chinese Spring, but a $\mathrm{BC}_{1}$ progeny was only obtained from the backcross with Chinese Spring. The $\mathrm{BC}_{1}$ plant was crossed with wheat cultivar Asakaze and 16 $\mathrm{BC}_{2}$ plants were grown to maturity. The presence of barley chromosomes in the wheat background was analysed in the $\mathrm{BC}_{2}$ plants with a combination of GISH and molecular markers, as reported earlier by Molnár-Láng et al. [14]. Ten ditelosomic addition lines (2HS, 2HL, 3HS, $3 \mathrm{HL}, 4 \mathrm{HS}, 4 \mathrm{HL}, 6 \mathrm{HS}, 6 \mathrm{HL}, 7 \mathrm{HS}$ and $7 \mathrm{HL}$ ) were selected from 860 self-fertilized progenies of the fertile $\mathrm{BC}_{2}$ plants (Fig. 1). The morphological traits of the plants were analysed in experiments carried out in phytotron climate chambers (Conviron PGV96) in 2013-2014 and in the field in the Tükrös nursery, Martonvásár, Hungary during the 2014-2015 growing season.

\section{In situ hybridization}

Mitotic chromosome spreads from germinating root tips were prepared as described by Lukaszewski et al. [15]. The ditelosomic addition lines were selected using GISH from the $\mathrm{BC}_{2} \mathrm{~F}_{2}-\mathrm{BC}_{2} \mathrm{~F}_{4}$ generations and identified by FISH using repetitive DNA probes. The GISH experiment was carried out as described by Molnár-Láng et al. [16]. Barley total genomic DNA was labelled with digoxigenin-11-dUTP (Roche Diagnostics, Mannheim, Germany) with a nick translation mix and used as a probe. Unlabelled wheat genomic DNA was used as blocking DNA at a ratio of 35:1. Detection was carried out with anti-digoxigeninRhodamine (Roche). The slides were mounted in Vectashield antifade solution (Vector Laboratories, Burlingame,

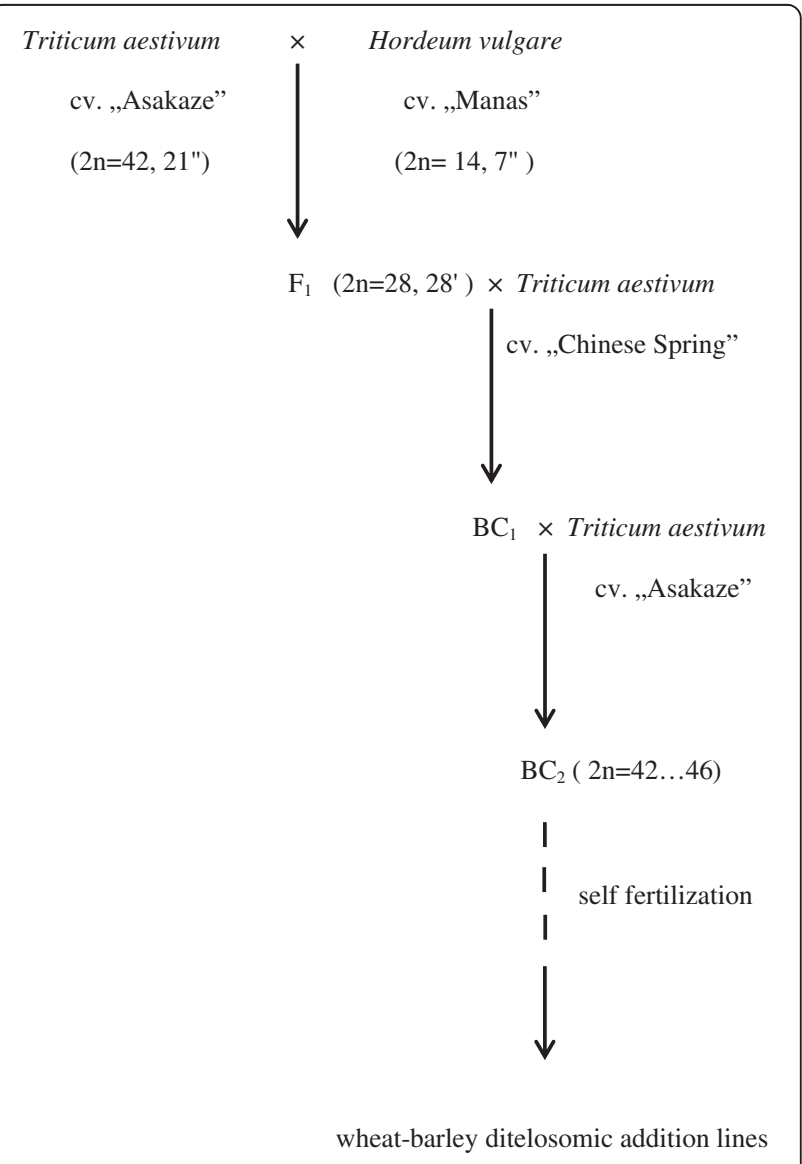

Fig. 1 Procedure for isolating barley chromosome ditelosomic addition lines in hexaploid wheat cultivar "Asakaze" 
USA) containing $2 \mu \mathrm{g} / \mathrm{mL}$ 4'-6-diamidino-2-phenylindole (DAPI). After rinsing off the GISH hybridization signals in $4 \times$ SSC Tween at room temperature, FISH was carried out using the (GAA) 7 microsatellite probe [17], the barley subtelomere-specific probe HvT01 [18] and barley centromere-specific sequences (AGGGAG) ${ }_{4}$ [19]. The $(\mathrm{GAA})_{7}$ microsatellite probe was amplified and labelled with biotin-16-dUTP using PCR. The barley subtelomeric sequence HvT01 was labelled combinatorially with $50 \%$ biotin-16-dUTP and $50 \%$ digoxigenin-11-dUTP. The barley centromere-specific sequences (AGGGAG) ${ }_{4}$ were labelled with digoxigenin-11-dUTP. Wheat-specific DNA repetitive probes (pSc119.2, Afa family and pTa71) were used to identify the presence of the entire wheat genome. The repetitive DNA sequences Afa family [20] and pSc119.2 [21] were amplified and labelled with digoxigenin-11-dUTP and biotin-16-dUTP, respectively, using PCR. The $45 \mathrm{~S}$ rDNA clone pTa71 [22] was labelled with $50 \%$ biotin-16dUTP and $50 \%$ digoxigenin-11-dUTP by nick translation. Digoxigenin and biotin signals were detected using antidigoxigenin-Rhodamine Fab fragments and streptavidinFITC (Roche), respectively. The slides were screened using a Zeiss Axioskop-2 fluorescence microscope equipped with filter sets appropriate for DAPI, FITC, Rhodamine and the simultaneous detection of FITC and Rhodamine (double filter set). Images were captured with a Spot CCD camera (Diagnostic Instruments, Sterling Heights, USA) and processed with Image Pro Plus software (Media Cybernetics, Silver Spring, USA).

\section{SSR and STS marker analysis}

Genomic DNA was extracted from fresh young leaves of wheat cultivar Asakaze, barley cultivar Manas and the ten Asakaze/Manas wheat-barley ditelosomic addition lines using Quick Gene-Mini80 (FujiFilm, Japan) with a QuickGene DNA tissue kit (FujiFilm, Japan) according to the manufacturer's instructions. The following set of barley chromosome arm-specific SSR markers and genespecific STS markers was selected: HvCSLF4-2HS [23], Bmag0125-2HL [24], HvLTPPB-3HS [24], HvM60-3HL [25], HvM40-4HS [25], HvM67-4HL [25], Bmac03166HS [24], EBmac0806-6HL [24], Bmac0031-7HS [24] and HvCslF6-7HL [23]. All the primer pairs were tested on DNA templates containing: genomic DNA from wheat cultivar Asakaze, barley cultivar Manas and the Asakaze/ Manas ditelosomic addition lines. The PCR amplification was performed under the conditions described by Molnár et al. [26]. The primer sequences and annealing temperatures used in this study are presented in Additional file 1. The PCR products were separated with a Fragment Analyzer $^{\text {rm }}$ Automated CE System equipped with a 96Capillary Array Cartridge (Advanced Analytical Technologies, USA). The results were analysed using PROsize v2.0 software (Advanced Analytical Technologies, USA).

\section{Phenotypic characterization of the plants, and statistical analysis}

The Asakaze/Manas wheat-barley ditelosomic addition lines $2 \mathrm{HS}, 2 \mathrm{HL}, 3 \mathrm{HS}, 3 \mathrm{HL}, 4 \mathrm{HS}, 4 \mathrm{HL}, 6 \mathrm{HS}, 6 \mathrm{HL}, 7 \mathrm{HS}$ and 7HL, the parental genotypes Asakaze, Chinese Spring and Manas and the Asakaze/Manas disomic addition lines were grown in phytotron chambers (Conviron PGV96) in Martonvásár. Vernalization was carried out at $4{ }^{\circ} \mathrm{C}$ for 6 weeks, and the plants were grown until tillering under an initial $15{ }^{\circ} \mathrm{C}$ day: $10{ }^{\circ} \mathrm{C}$ night temperature, $12 \mathrm{~h}$ light: $12 \mathrm{~h}$ dark photoperiod, $200 \mu \mathrm{mol} \mathrm{m}^{-2} \mathrm{~s}^{-1}$ light intensity (at pot level) and $75 \%$ relative humidity [27]. The temperature rose by increments of $2{ }^{\circ} \mathrm{C}$ after tillering (day length $14 \mathrm{~h}$ ), stem elongation (16 h illumination) and flowering, and 2 weeks after fertilization. The phenotypic analysis was performed on 10 plants from each genotype. The same genotypes were sown in the field in Martonvásár with 10 seeds in each $1 \mathrm{~m}$ row and a row distance of $15 \mathrm{~cm}$. Ten plants were randomly selected from each genotype for analysis. Plant height and tillering were determined immediately before harvest. The length of the main spike, spikelets/main spike, seeds/main spike and seeds/plant were measured after harvest.

The morphological traits of the ditelosomic addition lines were compared with those of the Asakaze and Chinese Spring wheat genotypes using Student's $t$ test for paired data at the $P=0.05$ significance level.

\section{Evaluation of the flowering date of Asakaze/Manas ditelosomic addition lines}

The flowering time of 10 plants was recorded for each genotype in the field experiment. Statistical analysis was performed using Student's t test for paired data on the flowering date and significant differences at the $P=0.05$ significance level.

\section{Evaluation of the salt stress response of Asakaze/Manas ditelosomic addition lines}

The salt stress response of seedlings of Asakaze/Manas ditelosomic addition lines was screened and compared to that of wheat and barley. The other wheat crossing parent Chinese Spring was not used in these investigations, as it had similar or lower salt tolerance than Asakaze, as demonstrated in earlier investigations [28]. In the germination test, $3 \times 20$ seeds of each genotype per treatment were surface-sterilized in $10 \%$ sodium hypochlorite for $15 \mathrm{~min}$, rinsed twice in distilled water and germinated on wet filter paper containing $0,100,200$ or $250 \mathrm{mM} \mathrm{NaCl}$ in Petri dishes for 3 days at a temperature of $25{ }^{\circ} \mathrm{C}$. The percentage of germinated seeds and the length and weight of roots and coleoptiles were determined. 


\section{Results}

Selection, identification and morphological characterization of the wheat-barley ditelosomic addition lines

All the barley chromosomes were present in one or more of the $16 \mathrm{BC}_{2}$ plants originating from the Asakaze $\times$ Manas hybrid with the exception of the complete $5 \mathrm{H}$, though $5 \mathrm{HS}$ was present in one plant. It was not possible to select lines with either the $1 \mathrm{H}$ or $5 \mathrm{HS}$ additions, because the $\mathrm{BC}_{2}$ plants carrying these barley chromosomes set no seed [9]. Ten wheat-barley ditelosomic additions were selected from the progenies of the $\mathrm{BC}_{2}$ plants. These lines were $2 \mathrm{HS}, 2 \mathrm{HL}$, $3 \mathrm{HS}, 3 \mathrm{HL}, 4 \mathrm{HS}, 4 \mathrm{HL}, 6 \mathrm{HS}, 6 \mathrm{HL}, 7 \mathrm{HS}$ and $7 \mathrm{HL}$. The presence of the barley telocentric chromosomes in the wheat background was detected using GISH (Fig. 2a). The telocentric barley chromosomes were identified using FISH (Fig. 2b) and barley-arm specific SSR and STS markers. The barley subtelomere-specific probe HvT01 and barley centromerespecific sequences (AGGGAG) ${ }_{4}$ were used to demonstrate that the entire barley chromosome arm was present in the relevant ditelosomic addition line. The presence of 42 wheat chromosomes was detected with wheat-specific DNA repetitive FISH probes (Fig. 3). The wheat-barley ditelosomic addition lines were developed from 860 progenies of selfed $\mathrm{BC}_{2}$ plants, mainly from monosomic addition lines, between 2010 and 2013. Thirty percent of these plants (260) were homozygous telosomic plants, while the barley chromosomes were eliminated from 46 \% (395) of the plants. Monotelosomic additions, Robertsonian translocations, mono- and disomic additions and isochromosomes were found among the lines investigated (Table 1).

The 2HS and 2HL ditelosomic addition lines were selected from a $2 \mathrm{H}$ monosomic addition. Some of its progenies carried telocentric chromosomes, which were

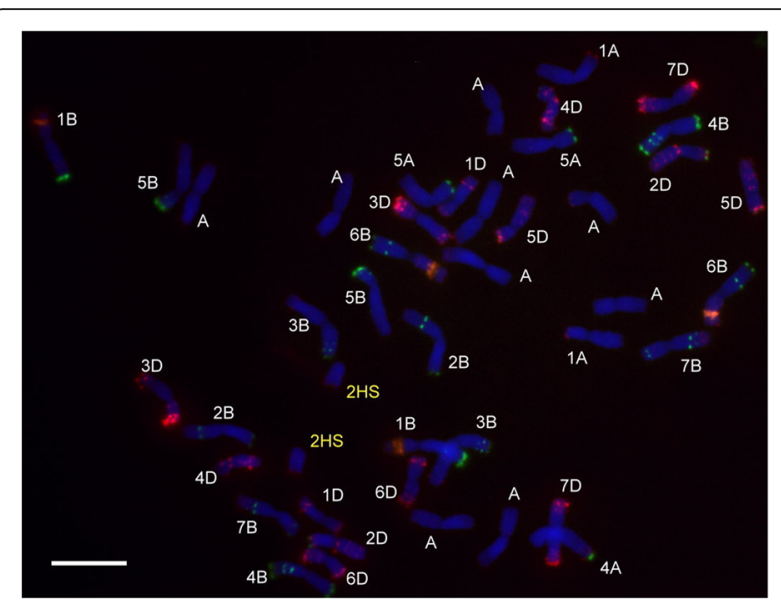

Fig. 3 Fluorescence in situ hybridization on mitotic chromosomes of the Asakaze/Manas wheat-barley 2HS ditelosomic addition with DNA repetitive probes: pSc119.2 (green), Afa family (red) and pTa71 (orange). Scale bar $10=\mu \mathrm{m}$

assumed to be $2 \mathrm{HS}$ or $2 \mathrm{HL}$ telocentrics. The barley telocentric chromosome pair was detected in the wheat background using GISH. The cytological analysis was followed by the identification of the alien chromatin using the HvCSLF4 STS marker to identify the 2HS arm and the Bmag0125 SSR marker for the 2HL chromosome arm (Fig. 4). The 2HS addition line had awnless, tapered spikes with a specific curvature and hard culm, while the spike of the $2 \mathrm{HL}$ addition plants was awnless with a laxed structure (Fig. 5). In the phytotron experiments the two lines showed significantly better tillering and number of seeds/plant than the Asakaze wheat genotype (Additional file 2).
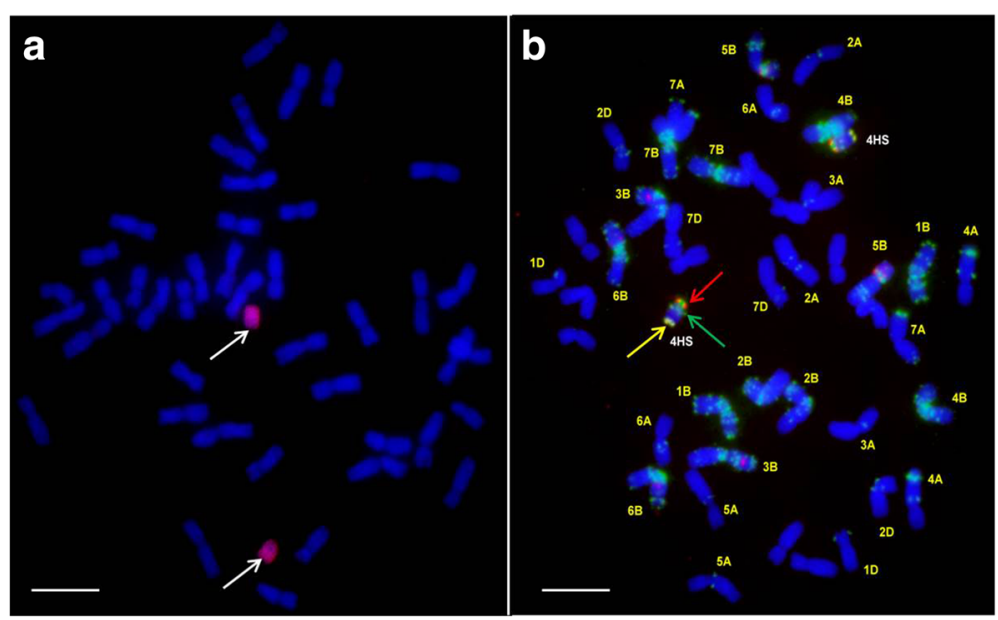

Fig. 2 a Genomic in situ hybridization on mitotic chromosomes of the 4HS Asakaze/Manas wheat-barley ditelosomic addition. The chromosomes were counterstained with DAPI (b/ue). Barley total genomic DNA is visualized in red (arrows). b Fluorescence in situ hybridization on mitotic chromosomes of the Asakaze/Manas wheat-barley 4HS ditelosomic addition with DNA repetitive probes: barley centromere-specific probe (red and red arrow), (GAA)7 microsatellite probe (green and green arrow) and HvT01 (yellow and yellow arrow). Scale bar 10 $=\mu \mathrm{m}$ 
Table 1 The number of seeds examined for the development of each wheat-barley ditelosomic addition line

\begin{tabular}{|c|c|c|c|c|c|}
\hline \multirow[t]{2}{*}{ Genotypes } & \multicolumn{5}{|c|}{ Barley chromosomes detected in the seeds analysed } \\
\hline & 2 telocentrics & 1 telocentric & Others & Barley chromosomes eliminated & Number of seeds examined \\
\hline $2 \mathrm{HS}$ & 17 & 6 & 0 & 14 & 37 \\
\hline $2 \mathrm{HL}$ & 19 & 4 & 6 & 17 & 46 \\
\hline $3 \mathrm{HS}$ & 51 & 19 & 1 & 38 & 109 \\
\hline $3 \mathrm{HL}$ & 12 & 24 & 3 & 86 & 125 \\
\hline $4 \mathrm{HS}$ & 33 & 45 & 1 & 115 & 194 \\
\hline $4 \mathrm{HL}$ & 23 & 10 & 0 & 16 & 49 \\
\hline $6 \mathrm{HS}$ & 13 & 19 & 25 & 56 & 113 \\
\hline $6 \mathrm{HL}$ & 29 & 13 & 0 & 6 & 48 \\
\hline 7HS & 10 & 6 & 0 & 8 & 24 \\
\hline $7 \mathrm{HL}$ & 53 & 17 & 6 & 39 & 115 \\
\hline$\Sigma$ & 260 & 163 & 42 & 395 & 860 \\
\hline
\end{tabular}

The 3HS chromosome addition was selected from the progenies of a $3 \mathrm{H}$ monosomic addition, while the $3 \mathrm{HL}$ was identified among the descendants of a $3 \mathrm{H}$ disomic addition. After detecting the barley chromatin using GISH, the 3HS and 3HL additions were identified with the help of the HvLPTTB and HvM60 SSR markers, respectively (Fig. 4). The 3HS line had laxed spikes with awnstubs, while the 3HL line had short, awnless spikes with a denser structure (Fig. 5). In both phytotron and field experiments the $3 \mathrm{HL}$ line had one of the shortest spikes of all the ditelosomic additions developed, yet the 1000-kernel weight calculated for the field experiment was better than that of almost all the other ditelosomic and disomic addition lines (Additional files 2 and 3).
The 4HS and 4HL ditelosomic addition lines were derived from the $4 \mathrm{H}$ monosomic addition line. Telocentric barley chromosomes were identified in the wheat background on the mitotic chromosome spreads of its progenies using GISH. The cytological identification was confirmed using SSR markers specific for the 4HS (HvM40) and 4HL (HvM67) barley chromosome arms (Fig. 4). The 4HS telocentric chromosome was eliminated from the analysed plants with the highest frequency (Table 1), while the homozygous 4 HS ditelosomic addition was quite stable. The 4HS line had flared spikes with awnstubs, while 4HL had shorter, dense spikes also possessing awnstubs (Fig. 5). The 4HL ditelosomic addition plants were the shortest in the series of ten ditelosomic addition lines; the plant height

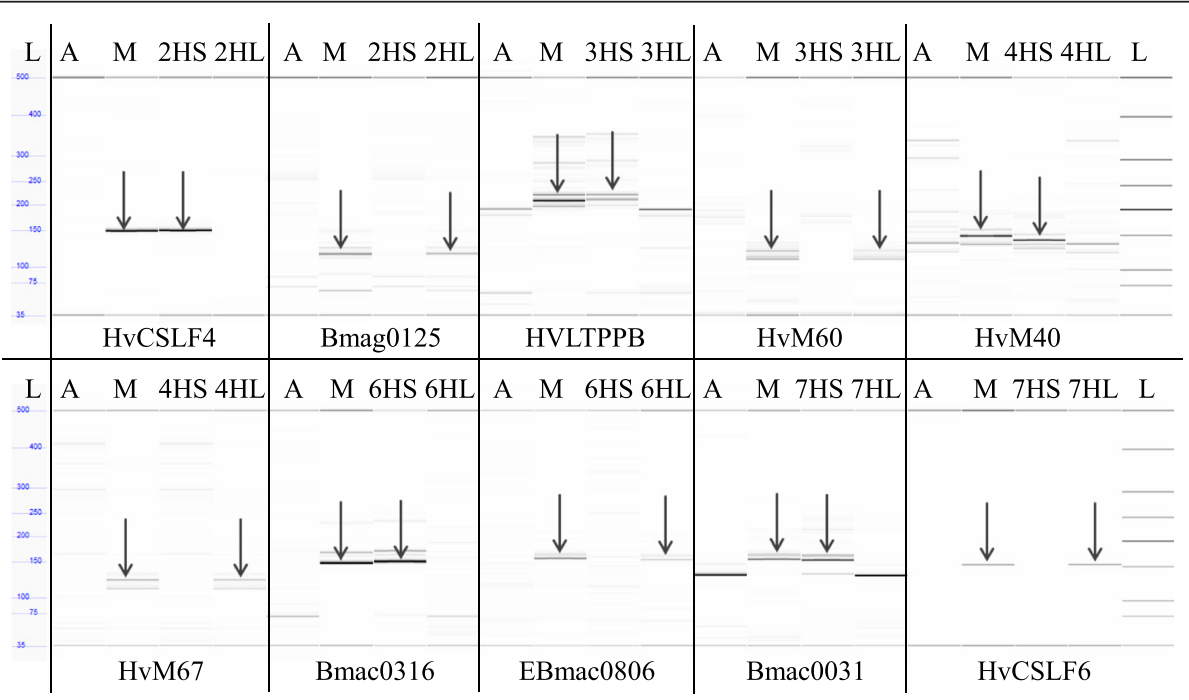

Fig. 4 Capillary gel electrophoresis pattern of the ditelosomic addition lines using HvCSLF4-2HS, Bmag0125-2HL, HvLTPPB-3HS, HvM60-3HL, HvM404HS, HvM67-4HL, Bmac0316-6HS, EBmac0806-6HL, Bmac0031-7HS and HvCSLF6-7HL barley chromosome arm-specific markers on the following DNA templates: Asakaze wheat (A), Manas barley (M), A/M ditelosomic addition lines (2HS, $2 \mathrm{HL} ; 3 \mathrm{HS}, 3 \mathrm{HL} ; 4 \mathrm{HS}, 4 \mathrm{HL} ; 6 \mathrm{HS}, 6 \mathrm{HL} ; 7 \mathrm{HS}$, $7 \mathrm{HL})$. Barley chromosome arm-specific bands are indicated by arrows. A 50-bp DNA ladder $(L)$ was used to estimate fragment size 


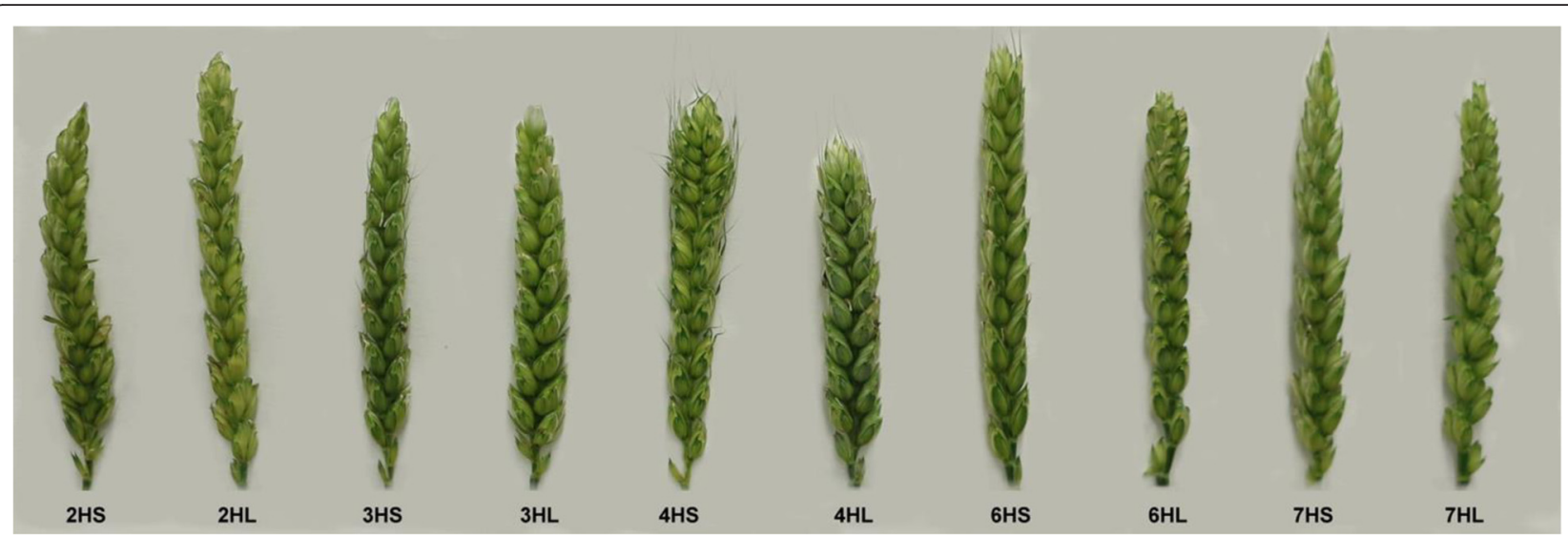

Fig. 5 Spike morphology of the ten Asakaze/Manas ditelosomic addition lines (typical spikes collected from the Tükrös nursery, Martonvásár, May 2015)

was significantly lower than that of the wheat genotypes both in the phytotron and in the field. The fertility of both the $4 \mathrm{HS}$ and $4 \mathrm{HL}$ lines was better than that of the other eight ditelosomic addition lines, both in the phytotron and in the field experiment (Additional files 2 and 3).

A double monosomic addition line carrying the $6 \mathrm{H}$ and $7 \mathrm{H}$ barley chromosomes was the parental genotype for the $6 \mathrm{HS}, 6 \mathrm{HL}$ and some of the 7HL wheat-barley ditelosomic additions. The telocentrics of the $6 \mathrm{H}$ chromosome were transmitted with higher frequency than that of the $7 \mathrm{H}$. The 7HS arm was not detected in the progenies of these plants. The arms of the $6 \mathrm{H}$ chromosome were detected using GISH and identified with barley arm-specific SSR markers. The Bmac0136 marker revealed the presence of the 6HS barley chromosome arm, while the EBmac0806 confirmed the presence of $6 \mathrm{HL}$ (Fig. 4). The $6 \mathrm{HS}$ line had long spikes with apical awnstubs, while the 6HL spike was awnless (Fig. 5).

The 7HS and 7HL addition lines were selected from the the progenies of the $7 \mathrm{H}$ monosomic addition. The cytogenetic identification of the barley chromatin in the wheat background was followed by SSR and STS marker analysis, using the Bmac0031 SSR and HvCSLF6 STS markers, which distinguished the 7HS and 7HL barley chromosome arms, respectively (Fig. 4). Though the 7HL ditelosomic adition line was stable, more than two telocentric chromosomes were detected in some of the mitotic chromosome spreads of homozygous plants. As GISH did not reveal the barley origin of these chromosomes, FISH was applied on the same chromosome preparations after washing off the GISH signals. Wheatspecific FISH probes (pSc119.2, Afa family and pTa71) were used to identify the fragmented wheat chromosome. In all the preparations analysed this was found to be the $4 \mathrm{~B}$ chromosome. Both the 7HS and 7HL additions had awnless spikes that were not very dense, but the 7HS spike was much longer (Fig. 5). In plants carrying the fragmented $4 \mathrm{~B}$ wheat chromosome, the spikes of the $7 \mathrm{HL}$ addition were much shorter and had very low fertility. The fertility of the 7HS line was also low, as its spikes had many sterile spikelets on the apical part.

During the propagation of the lines the stability of the lines was also investigated in the progenies of plants homozygous for the presence of the barley telocentric chromosomes. The stability of all ten ditelosomic adition lines was higher than $50 \%$ and varied from $57.14 \%$ for the $2 \mathrm{HS}$ addition (of 28 progenies of ditelosomics, 16 were also ditelosomics) and $100 \%$ for $2 \mathrm{HL}$ (all 26 progenies of plants homozygous for the barley telocentrics were also ditelosomics) (Table 2).

\section{Evaluation of flowering time of Asakaze/Manas ditelosomic addition lines in the field experiment}

The flowering time of the ditelosomic addition lines was evaluated in the field experiment together with that of the Asakaze/Manas disomic $2 \mathrm{H}, 3 \mathrm{H}, 4 \mathrm{H}, 6 \mathrm{H}$ and $7 \mathrm{H}$ addition lines, the Asakaze and Chinese Spring wheat cultivars and the Manas barley cultivar. The earliest flowering genotype was Manas, where all the main spikes of the ten assigned plants flowered between 4 and 6 May. The earliest addition

Table 2 Stability of the Asakaze/Manas ditelosomic addition lines, investigated in the progenies of homozygous ditelosomic plants

\begin{tabular}{llll}
\hline Genotypes & $\begin{array}{l}\text { Number of progenies of } \\
\text { ditelosomic analysed }\end{array}$ & $\begin{array}{l}\text { Ditelosomic } \\
\text { plants }\end{array}$ & $\begin{array}{l}\text { Rate of ditelosomics } \\
\text { among progenies }\end{array}$ \\
\hline $2 \mathrm{HS}$ & 28 & 16 & $57.14 \%$ \\
$2 \mathrm{HL}$ & 26 & 26 & $100 \%$ \\
$3 \mathrm{HS}$ & 36 & 30 & $83.33 \%$ \\
$3 \mathrm{HL}$ & 30 & 19 & $63.33 \%$ \\
$4 \mathrm{HS}$ & 45 & 38 & $84.44 \%$ \\
$4 \mathrm{HL}$ & 20 & 19 & $95 \%$ \\
$6 \mathrm{HS}$ & 44 & 28 & $63.63 \%$ \\
$6 \mathrm{HL}$ & 36 & 28 & $77.77 \%$ \\
$7 \mathrm{HS}$ & 23 & 18 & $78.26 \%$ \\
$7 \mathrm{HL}$ & 81 & 73 & $90.12 \%$ \\
\hline
\end{tabular}


line was 7HL, which began flowering on 7 May, followed immediately on 8 May by the Asakaze wheat cultivar and the $2 \mathrm{H}, 3 \mathrm{HS}, 3 \mathrm{HL}, 4 \mathrm{HL}, 7 \mathrm{HS}$ and $7 \mathrm{H}$ addition lines, though the flowering interval was longer for most of these lines than for the 7HL addition line. The latest flowering lines were $6 \mathrm{HS}$ and $6 \mathrm{HL}$ on 13 May and $6 \mathrm{H}$ on 15 May (Fig. 6, Table 3).

\section{Evaluation of the salt stress response of Asakaze/Manas ditelosomic addition lines}

Germination tests were used for evaluating the salt stress response of Asakaze/Manas ditelosomic addition lines. The results were compared with those of the wheat parent Asakaze and the barley parent Manas and the differences were presented in Fig. 7. Without salt treatment, the genotypes showed only slight variability. The ditelosomic addition lines $2 \mathrm{HL}$ and $4 \mathrm{HS}$ had better growth vigour than Asakaze, while lines $6 \mathrm{HS}, 6 \mathrm{HL}$ and 7HS had poorer vigour. The 2HL addition line exhibited higher root and shoot length than wheat Asakaze. The root growth (both length and weight) was also higher in ditelosomic line 4HS than in Asakaze. These differences were more pronounced under mild salt stress (100 $\mathrm{mM}$ salt treatment), but disappeared when higher salt concentrations (200 and $250 \mathrm{mM}$ ) were applied (Fig. 7). The salt-induced decrease in germination rate and root and shoot growth (both length and weight) was considerable in the case of the $4 \mathrm{HL}, 6 \mathrm{HS}$, $6 \mathrm{HL}$ and 7HS ditelosomic lines. Inversely, higher growth potential was retained under salt stress conditions in ditelosomic line 7HL and Manas, which had higher root and shoot lengths and weight data than Asakaze. However, it should also be mentioned that salt stress inhibited shoot growth more intensively than root growth. The severe (200 and $250 \mathrm{mM}$ ) salt treatment led to $1-2 \mathrm{~mm}$ shoot primordia, which made it impossible to discriminate between the genotypes, as indicated in Additional file 4.

In previous experiments several wheat/barley addition and translocation lines carrying chromosomes from different wheat and barley cultivars were studied for aluminium and salt tolerance [29, 30]. A comparison of the salt stress responses of Asakaze/Manas wheat-barley disomic addition lines $(2 \mathrm{H}, 3 \mathrm{H}, 3 \mathrm{HS}, 4 \mathrm{H}, 6 \mathrm{H}, 7 \mathrm{H}$ and $7 \mathrm{HL}$ ) to those of the parental genotypes (Asakaze, Manas and Chinese Spring) revealed that the disomic addition line $7 \mathrm{H}$ and the ditelosomic line 7HL exhibited higher salt tolerance both during germination and in the

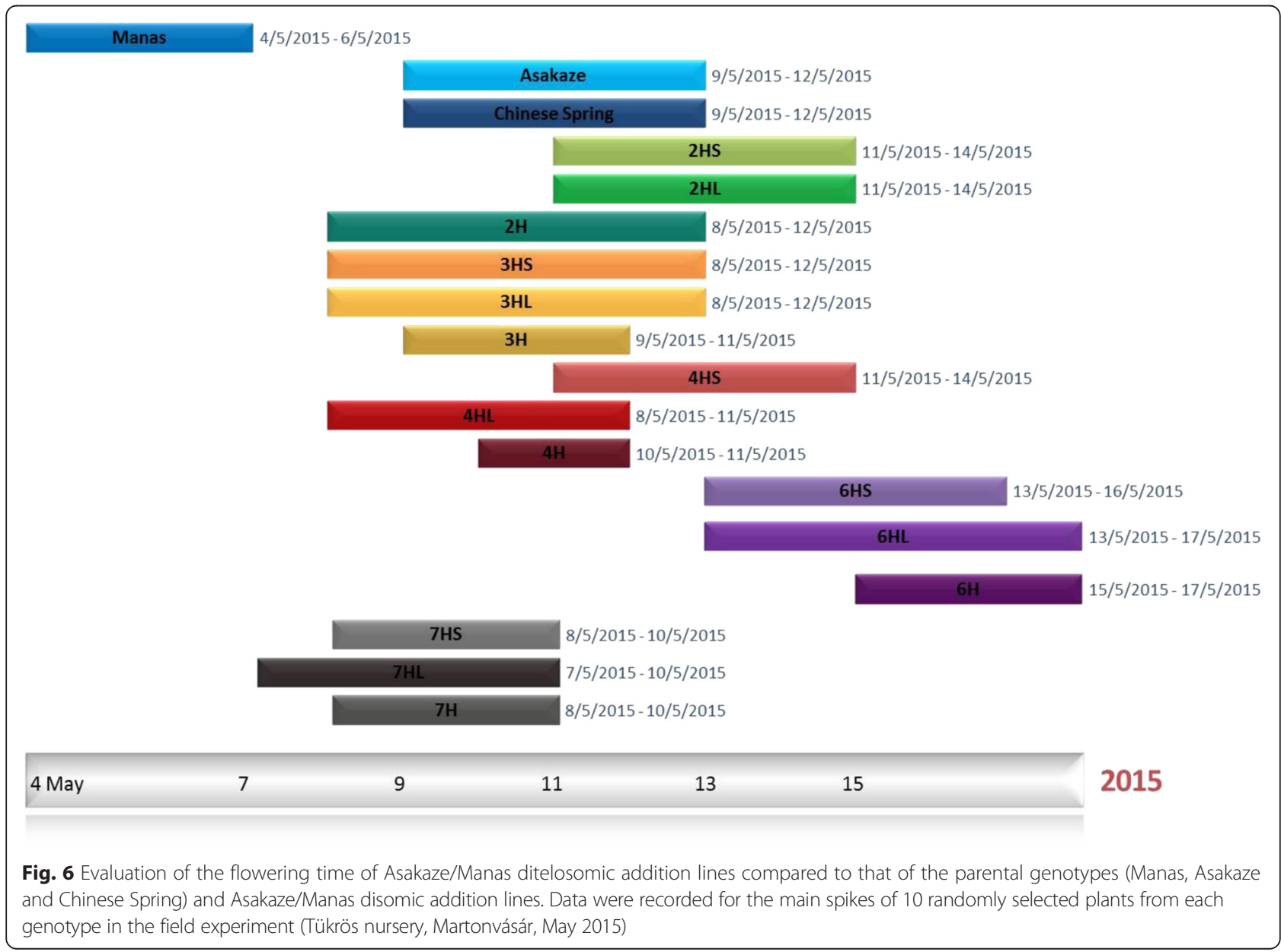


Table 3 Average flowering date of the genotype analysed (No. of days from 1st January 2015)

\begin{tabular}{|c|c|c|c|c|c|c|c|c|c|c|c|c|c|c|c|c|c|c|}
\hline Genotype & $2 \mathrm{HS}$ & $2 \mathrm{HL}$ & $2 \mathrm{H}$ & $3 \mathrm{HS}$ & $3 \mathrm{HL}$ & $3 \mathrm{H}$ & $4 \mathrm{HS}$ & $4 \mathrm{HL}$ & $4 \mathrm{H}$ & $6 \mathrm{HS}$ & $6 \mathrm{HL}$ & $6 \mathrm{H}$ & $7 \mathrm{HS}$ & $7 \mathrm{HL}$ & 7H & Asakaze & CS & Manas \\
\hline Average flowering date & $132.4^{a}, c_{1}$ & $131.6^{a b c}$ & 129.8 & $129.2^{b}$ & $130.3^{a}$ & $130^{\mathrm{a}}$ & $132.5^{a b}$ & $128.8^{b}$ & $130.8^{\mathrm{a}}$ & $134.2^{\mathrm{a}, \mathrm{b}}$ & $134.5^{a b}$ & $136^{a b}$ & $129.4^{b}$ & $128.7^{b}$ & $128.3^{b}$ & 129 & 130.4 & 124.7 \\
\hline Standard deviation & 1.35 & 1.26 & 1.13 & 1.14 & 1.34 & 0.67 & 0.97 & 1.31 & 0.42 & 1.14 & 1.59 & 0.81 & 0.70 & 1.16 & 0.67 & 0.81 & 1.07 & 0.82 \\
\hline
\end{tabular}

${ }^{2}$ Significantly different from the Asakaze wheat cultivar at the $P<0.05$ significance level

${ }^{\mathrm{b}}$ Significantly different from the Chinese Spring wheat cultivar at the $P<0.05$ significance level

cSignificantly different from the $2 \mathrm{H}$ line at the $P<0.05$ significance level 


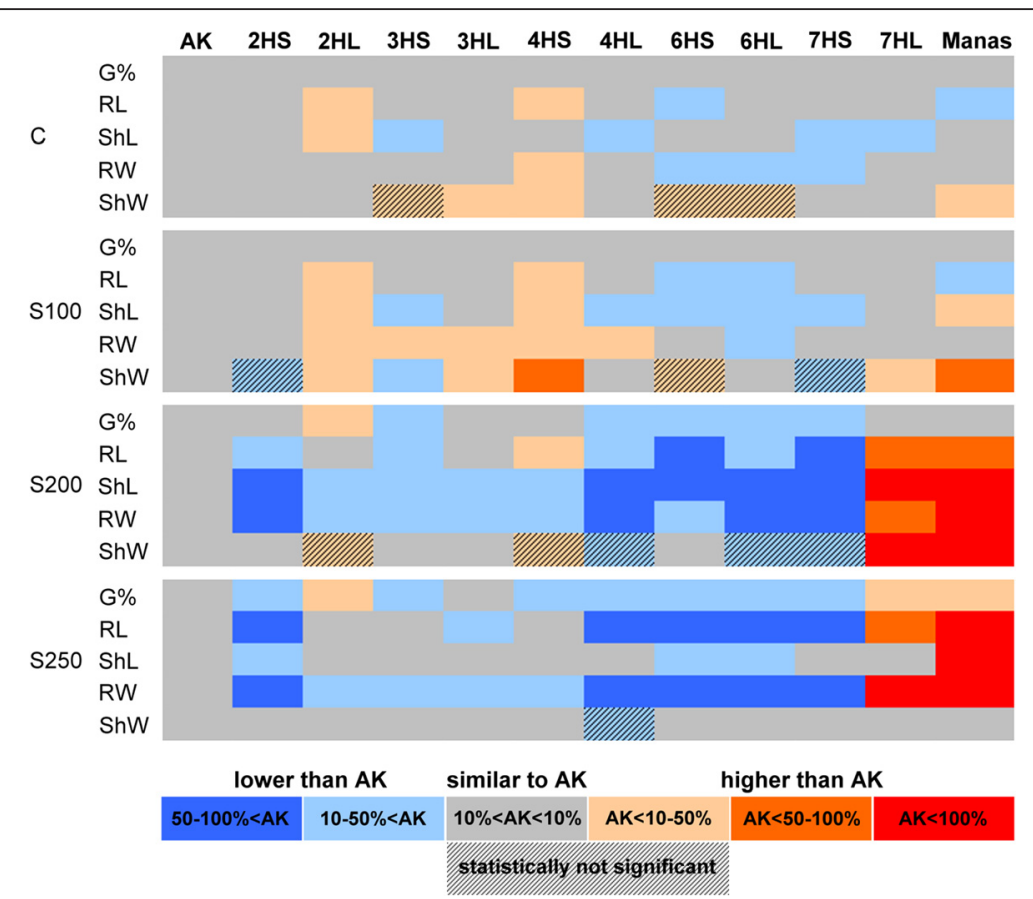

Fig. 7 Comparison of the germination properties (germination rate, G\%, root length, RL, shoot length, ShL, root weight, RW, shoot weight and ShW) of seedlings of wheat cultivar Asakaze (A), Asakaze/Manas ditelosomic addition lines and barley cultivar Manas in the control (C, without salt treatment) and under salt stress conditions induced by 100 mM (S100), 200 mM (S200) and 250 mM (S250) NaCl treatment. Grey blocks demonstrate that the values are similar (within $10 \%$ ) to those of wheat Asakaze. Reddish and blue blocks indicate higher and lower values than in wheat Asakaze, respectively. The absolute values are found Additional file 4

early developmental stages than the wheat parents, among which Asakaze had higher salt tolerance than Chinese Spring [30]. The present experiment using a set of ditelosomic lines $(2 \mathrm{HS}, 2 \mathrm{HL}, 3 \mathrm{HS}, 3 \mathrm{HL}, 4 \mathrm{HS}, 4 \mathrm{HL}, 6 \mathrm{HS}, 6 \mathrm{HL}$, 7HS and 7HL) confirmed the previous results. The ditelosomic line 7HS showed a higher reduction in growth under salt stress conditions than the wheat parent Asakaze, and the ditelosomic line 7HL and the barley parent Manas exhibited higher salt-tolerance at germination than Asakaze. These results suggest that lines carrying the long arm of the $7 \mathrm{H}$ barley chromosome in the wheat background could be used as genetic material for improving the salt tolerance of wheat. Higher root and shoot growth was also observed in the ditelosomic lines 2HL and 4HS than in wheat Asakaze during germination under control and mild salt stress conditions, but this improved vigour disappeared under severe salt stress, indicating that the intense growth was not related to the salt stress response. Intense root growth was also observed previously in $4 \mathrm{H}$ disomic addition lines [29], and the present results demonstrate that this is associated with the 4HS chromosome arm.

\section{Discussion}

The present paper reports the development of a new set of wheat-barley ditelosomic addition lines (2HS, 2HL, 3HS, $3 \mathrm{HL}, 4 \mathrm{HS}, 4 \mathrm{HL}, 6 \mathrm{HS}, 6 \mathrm{HL}, 7 \mathrm{HS}$ and $7 \mathrm{HL}$ ) obtained by incorporating the chromosomes of the six-rowed Ukrainian winter barley cultivar Manas into the facultative Japanese wheat cultivar Asakaze. The 5HS and 5HL ditelosomics could not be selected from the Asakaze/Manas combination, as the $5 \mathrm{H}$ chromosome was eliminated most frequently from the backcross progenies and the plant carrying the arms of this chromosome was sterile [14]. Each ditelosomic addition line developed contained the full complement of wheat chromosomes and a single telocentric chromosome pair from barley, though in some of the plants analysed wheat chromosome breakages or chromosome duplications were observed. Barley telocentric chromosomes may result from the misdivision of barley univalents during meiosis. The first and as yet only near complete set of wheat-barley ditelosomics, including 13 of the 14 possible ditelosomic addition lines (except 1HL) was produced by Islam in the 80 's through the addition of barley chromosomes from the Betzes barley cultivar to the Chinese Spring wheat cultivar. These lines were characterized on the basis of their morphological, physiological and biochemical features and the N-banding analysis of the chromosomes [10]. The newly developed Asakaze-Manas wheat-barley ditelosomic addition lines were identified using GISH, FISH and molecular marker analysis, while the morphological traits and yield components were studied in phytotron and field experiments. 
Manas is a winter barley cultivar with good winter hardiness making it better adapted to Central European climatic conditions than Betzes. It also has favourable agronomic traits, including good yielding ability [9] and better salt and aluminium tolerance than the other two barley genotypes previously used to develop addition lines [28-30]. Wheat-alien ditelosomic additions have also been developed using other cultivated and wild relatives of wheat, including various cultivars of rye, Aegilops species, Thinopyrum ponticum, Elymus species, Leymus racemosus and Hordeum chilense. These ditelosomic addition lines can be utilized for a wide range of purposes [31-40].

The development of Chinese Spring/Betzes wheat-barley ditelosomic additon lines opened the door for the flow sorting of barley telocentric chromosomes at high purity [41], making it possible to construct chromosome armspecific DNA libraries and to perform the cytogenetic mapping needed for the development of physical contig maps [42]. Mayer et al. [43] reported the use of flow-sorted barley chromosome $1 \mathrm{H}$ and chromosome arms $2 \mathrm{HS}$ to7HL to construct a high resolution sequence-based gene map containing an estimated $86 \%$ of the genes in the barley genome. It also proved possible to strech flow-sorted plant chromosomes longitudinally, thus increasing the physical resolution of maps constructed using FISH [44].

The most widespread wheat-alien introgression is the 1BL.1RS wheat-rye tranlocation where the 1RS chromosome arm carries resistance genes to biotic and abiotic stresses, and genes affecting yield potential or protein content. The 1BL.1RS translocation is present in several hundreds of wheat cultivars, and has therefore received great attention from researchers and breeders. Flowsorted 1RS chromosomes from the 1RS wheat-rye (Chinese Spring-Imperial) ditelosomic addition line were used to construct BAC libraries specific for 1RS rye chromosome. Chromosome arm-specific BAC libraries make it possible the high-resolution analysis of a particular region of complex plant genomes and developing molecular markers for these regions [45].

With the help of the Chinese Spring-Aegilops geniculata $5 \mathrm{M}^{\mathrm{g}}$ ditelosomic addition line, the arm of an Aegilops chromosome, was successfully flow-sorted for the first time and sequenced using Illumina technology. Next-generation sequencing offers a cheap way to develop sequence-based markers for the molecular analysis of Aegilops chromosomes [46].

The Asakaze/Manas wheat-barley ditelosomic addition lines were compared with the Asakaze/Manas disomic addition lines, previously selected from the same wheatbarley cross [9]. As aneuploids, disomic and ditelosomic additions exhibit a certain degree of instability which necessitates regular cytological analysis. Based on the experiments carried out to date it can be concluded that the Asakaze/Manas ditelosomic addition lines are more stable than the disomic addition lines. The $3 \mathrm{H}$ disomic addition, in particular, showed an unexpectedly high level of chromosome instability in comparison with that developed from Mv9kr1 and Igri $[9,47]$, while both $3 \mathrm{HS}$ and $3 \mathrm{HL}$ were more stable during the propagation of the ditelosomic addition lines (Table 2). The transmission of the alien chromosomes was more reliable when single alien chromosomes were replaced by their telocentrics [48].

Differences were revealed in the plant and spike morphology and in the fertility of ditelosomic additions compared with those of disomic addition lines. The 4HL addition was the shortest of all the ditelosomic addition lines and the plants were also significantly shorter than the wheat parental genotypes, both in the phytotron and in the field. The 6HS, $6 \mathrm{HL}$ and 7HS additions had the longest spikes among the ditelosomic additions, while 4HS and 4HL had significantly shorter spikes but better fertility than the wheat parental genotypes (Figs. 5 and 8). This was especially true of $4 \mathrm{HL}$, which had spikes with a dense

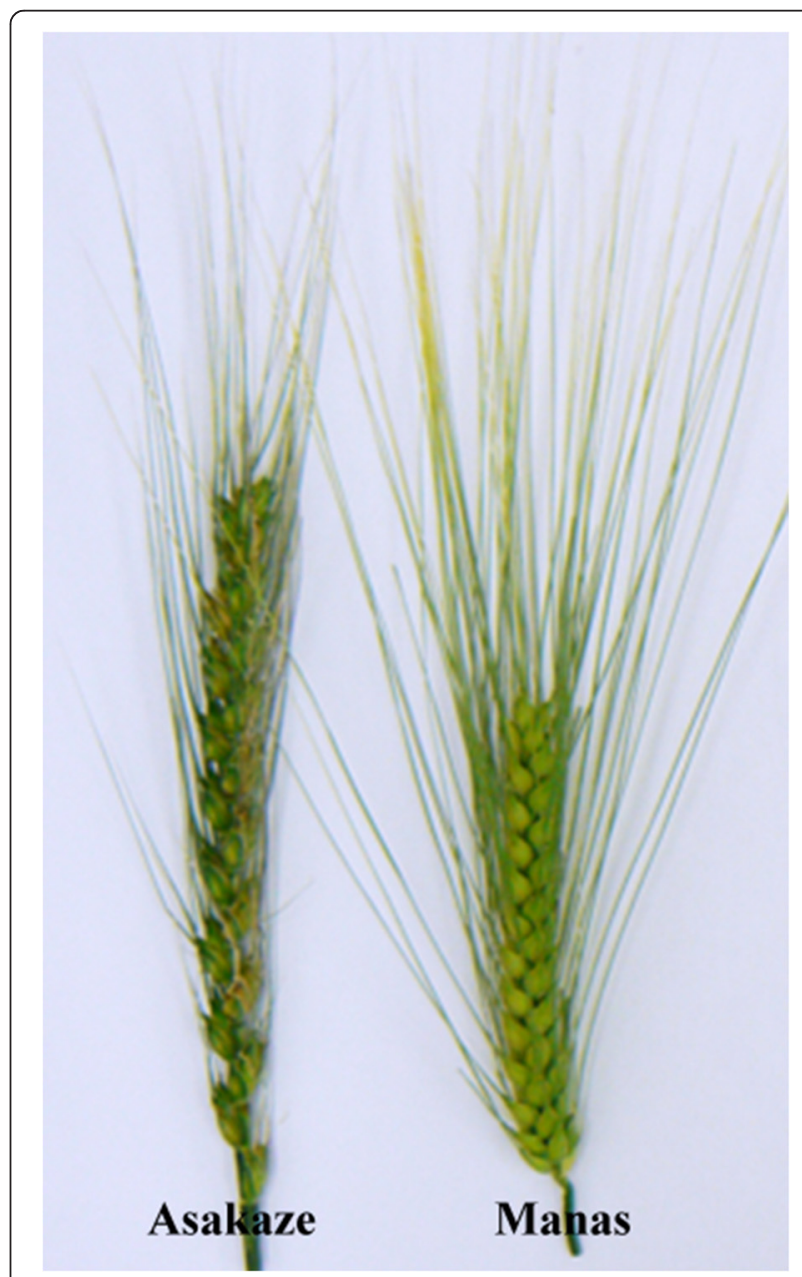

Fig. 8 Spike morphology of wheat cultivar Asakaze and barley cultivar Manas (typical spikes collected from the Tükrös nursery, Martonvásár, May 2015) 
structure and a significantly higher number of seeds/spike than Asakaze and Chinese Spring in the experiment carried out in the Tükrös nursery. While the $7 \mathrm{H}$ disomic addition line had the lowest fertility ([9] and data presented in this work) and that of 7HL was the lowest of all the ditelosomics, 7HS exhibited higher fertility in the field. The addition line carrying the 7HL chromosome arm was the earliest flowering of the addition lines, flowering later than Manas but earlier than the wheat genotypes, whereas the latest flowering lines were those carrying the entire $6 \mathrm{H}$ or the telocentric $6 \mathrm{HS}$ and $6 \mathrm{HL}$ chromosomes. These results are in agreement with data previously presented by Molnár-Láng et al. [49]. In the field experiment the $2 \mathrm{H}$ disomic addition line flowered significantly earlier than lines carrying the short or long arm of this barley chromosome. The major photoperiod sensitivity locus Ppd-H1 located on $2 \mathrm{HS}$, results in accelerated plant development under a long photoperiod in barley [50,51]. Winter barleys require vernalization and flowering is usually promoted by long days. Dominant alleles at Ppd-H1 confer early flowering under long days, but have no effect under short days. The $2 \mathrm{H}$ chromosome also contains many important genes for barley development and adaptation, such as row-type vrs 1 [52], earliness per se (eps2S) [53, 54] and early maturity Eam1 [55]. Further genetic and genomic studies will be required to determine how these genes located on the short or long arms of chromosome $2 \mathrm{H}$ function separately in a wheat background.

Introgression lines are useful for investigating heterologous expression of genes from alien chromosomes in the wheat genetic background [56]. In previous experiments several wheat/barley addition and translocation lines carrying chromosomes from different wheat and barley cultivars were studied for aluminium and salt tolerance $[29,30]$. A comparison of the salt stress responses of Asakaze/Manas wheat-barley disomic addition lines $(2 \mathrm{H}, 3 \mathrm{H}, 3 \mathrm{HS}, 4 \mathrm{H}, 6 \mathrm{H}, 7 \mathrm{H}$ and $7 \mathrm{HL})$ to those of the parental genotypes (Asakaze, Chinese Spring and Manas) revealed that the disomic addition line $7 \mathrm{H}$ and the ditelosomic line $7 \mathrm{HL}$ exhibited higher salt tolerance both during germination and in the early developmental stages than the wheat parents, among which Asakaze had higher salt tolerance than Chinese Spring [28]. The present experiment, using a set of ditelosomic lines $(2 \mathrm{HS}, 2 \mathrm{HL}, 3 \mathrm{HS}, 3 \mathrm{HL}, 4 \mathrm{HS}, 4 \mathrm{HL}, 6 \mathrm{HS}$, $6 \mathrm{HL}, 7 \mathrm{HS}$ and $7 \mathrm{HL}$ ), confirmed the previous results. The ditelosomic line 7HS exhibited a greater reduction in growth under salt stress conditions than the wheat parent Asakaze, while ditelosomic line 7HL and the barley parent Manas had better salt-tolerance in the germination stage than Asakaze. These results suggest that lines carrying the long arm of $7 \mathrm{H}$ barley chromosome in the wheat background could be useful genetic material for improving the salt tolerance of wheat. Higher root and shoot growth was also observed in the ditelosomic lines 2HL and 4HS than in Asakaze during germination under control and mild salt stress conditions, but this improved vigour disappeared under severe salt stress, indicating that the intense growth was not related to the salt stress response. Intense root growth was also observed previously in $4 \mathrm{H}$ disomic addition lines [29], and the present results demonstrated that this is associated with the 4HS chromosome arm.

Disomic and ditelosomic addition lines can also be used for the development of wheat-alien translocation lines, which are more stable than additions. The progenies of a monosomic $7 \mathrm{H}$ addition line originating from the Asakaze $\times$ Manas hybrid were screened for the presence of barley chromatin, revealing the presence of a 4BS.7HL wheat-barley Robertsonian translocation [57]. An increased $(1,3 ; 1,4)$ - $\beta$-D-glucan level was detected in the translocation line, demonstrating that the HvCSLF6 gene, present on the centromeric region of the 7HL chromosome arm and responsible for $\beta$-glucan production, was expressed in the genetic background of hexaploid wheat. Based on this knowledge, a compensating 7BS.7HL wheat-barley Robertsonian translocation has been developed, as homoeologous chromosomes of barley are better able to compensate the loss of a certain wheat chromosome. The 7BS.7HL translocation line was developed from a cross between the 7B monosomic Rannaya wheat cultivar and the $7 \mathrm{H}$ Asakaze/Manas disomic addition. Plants carrying 42 chromosomes (monosomic for the $7 \mathrm{~B}$ wheat chromosome and for the $7 \mathrm{H}$ barley chromosome) were selected from the $F_{1}$ generation using GISH. The $F_{1}$ plants were self-fertilized and the presence of the short or long arm of the $7 \mathrm{H}$ barley chromosome was detected using $7 \mathrm{H}$ arm-specific molecular markers in the $\mathrm{F}_{2}$ generation. Six plants carrying a monosomic 7BS.7HL centric fusion were selected from the $F_{3}$ generation and were selfed. In the $F_{4}$ generation three plants with 42 chromosomes were identified as disomic 7BS.7HL translocations using GISH, FISH and molecular markers [58]. The $(1,3 ; 1,4)-\beta$-D-glucan content of the seeds will be determined after the propagation of these lines. If the HvCslF6 gene is expressed in this background, the 7BS.7HL Robertsonian translocation stock could be of potential importance for the manipulation of wheat $(1,3 ; 1,4)-\beta$-D-glucan levels.

\section{Conclusions}

The present study reports the development of a set of wheat-barley ditelosomic addition lines and ways in which these lines could be used in breeding programmes and for basic research. Several of the agronomic characters of the Manas barley cultivar are better than those of the Betzes cultivar previously used for the development of wheat-barley ditelosomic addition lines. The analysis 
of the salt tolerance of lines carrying the 7HL chromosome arm is the first step in exploitation of these traits. However, if this genetic material is to be used in wheat breeding, it will be necessary to develop wheat-barley translocation lines carrying only a small fragment of the barley chromatin.

\section{Additional files}

Additional file 1: STS and SSR markers used in the present study, the primer sequences, the annealing temperature and the size of PCR products. (DOCX $16 \mathrm{~kb}$ )

Additional file 2: Morphological traits of the Asakaze/Manas wheat-barley ditelosomic addition lines, the parental wheat cultivars and Asakaze/Manas disomic addition lines in experiments carried out in the Martonvásár phytotron between December 2013 and March 2014. \#: significantly different from Asakaze, \#\#: significantly different from Chinese Spring, \#\#\#: significantly different from Asakaze and Chinese Spring at $P=0.05$.

(DOCX $17 \mathrm{~kb}$ )

Additional file 3: Morphological traits of the Asakaze/Manas wheat-barley ditelosomic adittion lines, the parental wheat cultivars and Asakaze/Manas disomic addition lines in the Martonvásár nursery during the 2014-2015 growing season. \#: significantly different from Asakaze, \#\#: significantly different from Chinese Spring, \#\#\#: significantly different from Asakaze and Chinese Spring at $P=0.05$. (DOCX $19 \mathrm{~kb}$ )

Additional file 4: Effect of salt stress on the germination properties of seedlings of Asakaze/Manas ditelosomic addition lines, the wheat parent Asakaze and the barley parent Manas. The data are mean values \pm standard deviation for each treatment. Significant differences were determined using Tukey's post hoc test and different letters indicate significant differences between the genotypes and treatments at the $P \leq 0.05$ level. "-" indicates that the drastic reduction caused by salt treatment prevented statistical analysis and the comparison of the genotypes. (DOC $117 \mathrm{~kb}$ )

\section{Abbreviations}

DAPI, 4'-6-diamidino-2-phenylindole; FISH, fluorescence in situ hybridization; GISH, genomic in situ hybridization; PCR, polymerase chain reaction; SSC, saline sodium citrate; SSR, simple sequence repeat; STS, sequence tagged site

\section{Acknowledgments}

This work was funded by the Hungarian National Scientific Research Fund (OTKA K 104382 and K112226). The research leading to these results has received funding from the European Community's Seventh Framework Programme (FP7/2007-2013) under the grant agreement n FP7-613556, Whealbi. AC gratefully acknowledges support from a Marie Curie Fellowship Grant (FP7-PEOPLE-2013-IEF-625671) under the seventh framework program of the European Union. The authors gratefully acknowledge the excellent technical assistance of J. Bucsi, B. Bucsi and F. Tóth. Thanks are due to Barbara Hooper for revising the manuscript linguistically.

\section{Availability of supporting data}

The data set supporting the results give in this paper is included in or referred to within the paper or in the additional files.

\section{Authors' contributions}

MML provided the genetic material for the development of the ditelosomics, designed the experiment and revised the manuscript. ET carried out the molecular cytogenetic analysis, selected the ditelosomics and carried out the morphological analysis of the plants. AC accomplished the molecular marker analysis. ÉD determined the salt response of the seedlings. ET wrote the paper. All authors read and approved the final manuscript.

\section{Authors' information}

For all correspondence please contact MML.

\section{Competing interests}

The authors declare that they have no competing interests.
Consent for publication

Not applicable.

Ethics approval and consent to participate

Not applicable.

Received: 4 May 2016 Accepted: 7 June 2016

Published online: 21 June 2016

\section{References}

1. Farrer W. Some notes on the wheat "Bobs"; its peculiarities, economic value, and origin. Agric Gaz NSW. 1904;15:849-54.

2. Kruse A. Hordeum $\times$ Triticum hybrids. Hereditas. 1973;73:157-61.

3. Islam AKMR, Shepherd KW. Incorporation of barley chromosomes into wheat. In: Bajaj YP, editor. Biotechnology in agriculture and forestry wheat, vol. 13. Heidelberg: Springer; 1990. p. 128-51.

4. Islam AKMR, Shepherd KW. Isolation of a fertile wheat-barley addition line carrying the entire barley chromosome 1H. Euphytica. 2000;111:145-9.

5. Molnár-Láng M, Linc G, Szakács É. Wheat-barley hybridization: The last 40 years. Euphytica. 2014;195:315-29.

6. Islam AKMR, Shepherd KW, Sparrow DHB. Isolation and characterization of euplasmic wheat-barley chromosome addition lines. Heredity. 1981;46:161-74.

7. Islam AKMR, Shepherd KW, Sparrow DH. Production and characterization of wheat-barley addition lines. In: Proceedings of 5th International Wheat Genetic Symposium. Ramanujam S. New Delhi ed. India: Science Publishers Inc.; 1978. p. 365-71.

8. Molnár-Láng M, Linc G, Sutka J. Production and molecular cytogenetic identification of wheat-barley hybrids and translocations. J Plant Biotechnol. 1999;1:8-12.

9. Molnár-Láng M, Kruppa K, Cseh A, Bucsi J, Linc G. Identification and phenotypic description of new wheat - six-rowed winter barley disomic additions. Genome. 2012;55:302-11.

10. Islam AKMR. Ditelosomic additions of barley chromosomes to wheat. In: Proceedindgs of 6 th international wheat Genetics Symposium. Sakamoto S. ed. Kyoto, Japan: Kyoto University Press; 1983. p. 233-8.

11. Cho S, Garvin DF, Muehlbauer GJ. Transcriptome analysis and physical mapping of barley genes in wheat-barley chromosome addition lines. Genetics. 2006;172:1277-85.

12. Bilgic H, Cho S, Garvin DF, Muehlbauer GJ. Mapping barley genes to chromosome arms by transcript profiling of wheat-barley ditelosomic chromosome addition lines. Genome. 2007:50:898-906.

13. Molnár-Láng M, Linc G, Logojan A, Sutka J. Production and meiotic pairing behaviour of new hybrids of winter wheat (Triticum aestivum) $\times$ winter barley (Hordeum vulgare). Genome. 2000:43:1045-54.

14. Molnár-Láng M, Novotny C, Linc G, Nagy ED. Changes in the meiotic pairing behaviour of a winter wheat-winter barley hybrid maintained for a long term in tissue culture, and tracing the barley chromatin in the progeny using GISH and SSR markers. Plant Breeding. 2005;124:247-52.

15. Lukaszewski AJ, Rybka K, Korzun V, Malyshev SV, Lapinski B, Whitkus R. Genetic and physical mapping of homoeologous recombination points involving wheat chromosome $2 \mathrm{~B}$ and rye chromosome 2R. Genome. 2004:47:36-45.

16. Molnár-Láng M, Cseh A, Szakács É, Molnár I. Development of a wheat genotype combining the recessive crossability alleles $k r 1 k r 1 k r 2 k r 2$ and the 1BL.1RS translocation, for the rapid enrichment of 1RS with new allelic variation. Theor Appl Genet. 2010;120:1535-45

17. Pedersen C, Linde-Laursen I. Chromosomal locations of four minor rDNA loci and a marker microsatellite sequence in barley. Chromosome Res. 1994:2:65-71.

18. Schubert I, Shi F, Fuchs J, Endo TR. An efficient screening for terminal deletions and translocations of barley chromosomes added to common wheat. Plant J. 1998;14:489-95.

19. Hudakova S, Michalek W, Presting GG, ten Hoopen R, dos Santos K, Jasencakova Z, Schubert I. Sequence organization of barley centromeres. Nucleic Acids Res. 2001:29:5029-35

20. Nagaki K, Tsujimoto H, Isono K, Sasakuma T. Molecular characterization of a tandem repeat, Afa family, and its distribution among Triticeae. Genome. 1995:38:479-86.

21. Bedbrook JR, Jones J, O'Dell M, Thompson RD, Flavell RB. A molecular description of telomeric heterochromatin in secale species. Cell. 1980;19: 545-60. 
22. Gerlach WL, Bedbrook JR. Cloning and characterization of ribosomal RNA genes from wheat and barley. Nucleic Acids Res. 1979;7:1869-85.

23. Burton RA, Jobling SA, Harvey AJ, Shirley NJ, Mather DE, Bacic A, Fincher GB. The genetics and transcriptional profiles of the cellulose synthase-like HvCs/F gene family in barley. Plant Physiol. 2008;146:1821-33.

24. Ramsay L, Macaulay M, Degli IS, MacLean K, Cardle L, Fuller J, et al. A Simple Sequence Repeat-Based Linkage Map of Barley. Genetics. 2000;156:1997-2005.

25. Liu ZW, Biyashev RM, Maroof MA. Development of simple sequence repeat DNA markers and their integration into a barley linkage map. Theor Appl Genet. 1996;93:869-76.

26. Molnár I, Kubaláková M, Šimková H, Farkas A, Cseh A, Megyeri M, Vrána J, Molnár-Láng M, Doležel J. Flow cytometric chromosome sorting from diploid progenitors of bread wheat, T. urartu, Ae. speltoides and Ae. tauschii. Theor Appl Genet. 2014;127:1091-104.

27. Tischner T, Kőszegi B, Veisz O. Climatic programms used in the Martonvasar phytotron most frequently in recent years. Acta Agron Hung. 1997;45:85-104.

28. Darkó É, Janda T, Majláth I, Szopkó D, Dulai S, Molnár I, Türkösi E, Molnár-Láng M. Salt stress response of wheat-barley addition lines carrying chromosomes from the winter barley "Manas.". Euphytica. 2015;203:491-504.

29. Dulai S, Molnár I, Haló B, Molnár-Láng M. Photosynthesis in the 7H Asakaze komugi/Manas wheat/barley addition line during salt stress. Acta Agron Hung. 2010;58:367-76.

30. Darkó É, Barnabás B, Molnár-Láng M. Characterization of newly developed wheat/barley introgression lines in respect of aluminium tolerance. Am J Plant Sci. 2012;3:1462-9.

31. Riley R, Chapman V, Johnson R. The incorporation of alien disease resistance in wheat by genetic interference with the regulation of meiotic chromosome synapsis. Genet Res. 1968;12:199-219.

32. Driscoll C, Sears ER. Individual addition of the chromosomes of "Imperial" rye to wheat. Agron Abst. 1971;6.

33. Dvorak J, Knott DR. Disomic and Ditelosomic Additions of Diploid Agropyron elongatum Chromosomes to Triticum Aestivum. Can J Genet Cytol. 1974;16:399-417.

34. Miller TE, Reader SM, Chapman V. The addition of Hordeum chilense chromosomes to wheat. In: Induced variability in Plant Breeding. C. Pudoc ed. Wageningen: Proc Eucarpia Symp, Wageningen, The Netherlands; 1982. p. 79-81.

35. Friebe B, Tuleen NA, Gill BS. Standard karyotype of Triticum searsii and its relationship with other S-genome species and common wheat. Theor Appl Genet. 1995:91:248-54.

36. Friebe B, Tuleen N, Jiang J, Gill BS. Standard karyotype of Triticum longissimum and its cytogenetic relationship with T. aestivum. Genome. 1993;36:731-42.

37. Friebe B, Jiang J, Tuleen N, Gill BS. Standard karyotype of Triticum umbellulatum and the characterization of derived chromosome addition and translocation lines in common wheat. Theor Appl Genet. 1995;90:150-6.

38. Friebe BR, Tuleen NA, Gill BS. Development and identification of a complete set of Triticum aestivum - Aegilops geniculata chromosome addition lines. Genome. 1999:42:374-80.

39. Friebe B, Qi LL, Nasuda S, Zhang P, Tuleen NA, Gill BS. Development of a complete set of Triticum aestivum-Aegilops speltoides chromosome addition lines. Theor Appl Genet. 2000;101:51-8.

40. Wang SL, Qi LL, Chen PD, Liu DJ, Friebe B, Gill BS. Molecular cytogenetic identification of wheat-Elymus tsukushiense introgression lines. Euphytica. 1999;107:217-24.

41. Suchánková P, Kubaláková M, Kovářová P, Bartoš J, Číhalíková J, Molnár-Láng $M$, Endo TR, Doležel J. Dissection of the nuclear genome of barley by chromosome flow sorting. Theor Appl Genet. 2006;113:651-9.

42. Harper LC, Cande WZ. Mapping a new frontier; development of integrated cytogenetic maps in plants. Funct Integr Genomics. 2000;1:89-98.

43. Mayer KFX, Martis M, Hedley PE, Simková H, Liu H, Morris JA, et al. Unlocking the barley genome by chromosomal and comparative genomics. Plant Cell. 2011;23:1249-63.

44. Valárik M, Bartoš J, Kovárová P, Kubaláková M, de Jong JH, Dolezel J. Highresolution FISH on super-stretched flow-sorted plant chromosomes. Plant J. 2004;37:940-50.

45. Bartoš J, Paux E, Kofler R, Havránková M, Kopecký D, Suchánková P, Šafár J, Šimková $H$, Town CD, Lelley T, Feuillet C, Doležel J. A first survey of the rye (Secale cereale) genome composition through BAC end sequencing of the short arm of chromosome 1R. BMC Plant Biol. 2008;8:95.
46. Tiwari VK, Wang S, Sehgal S, Vrána J, Friebe B, Kubaláková M, Chhuneja P, Doležel J, Akhunov E, Kalia B, Sabir J, Gill BS. SNP Discovery for mapping alien introgressions in wheat. BMC Genomics. 2014;15:1-11.

47. Szakács $E$, Molnár-Láng M. Identification of new winter wheat - winter barley addition lines (6HS and $7 \mathrm{H}$ ) using fluorescence in situ hybridization and the stability of the whole "Martonvásári 9 kr1" - "Igri" addition set. Genome. 2010;53:35-44.

48. Yasui H, Iwata N. Cytogenetics of ditelosomic alien addition lines in rice (Oryza sativa L.) each carrying an extra pair of telocentric chromosomes of O. punctata Kotschy. J Fac Agr - Kyushu Univ (Japan). 1998;43:1-9.

49. Molnár-Láng M, Türkösi E, Farkas A, Cseh A, Kruppa K, Icsó D, Rakszegi M, Szakács É, Hoffmann B, Linc G. Evaluation of flowering time, B-glucan content and tillering of wheat/barley introgression lines. In: Cereals for Food, Feed and Fuel, Challenge for Global Improvement: Eucarpia Cereals Section - ITMI Joint Conference, Book of Abstract. 359 p. Lohwasser U, Börner A.eds. Wernigerode, Germany; 2014:60.

50. Cockram J, Jones H, Leigh FJ, O'Sullivan D, Powell W, Laurie DA, Greenland AJ. Control of flowering time in temperate cereals: genes, domestication, and sustainable productivity. J Exp Bot. 2007;58:1231-44.

51. Turner A, Beales J, Faure S, Dunford RP, Laurie DA. The pseudo-response regulator Ppd-H1 provides adaptation to photoperiod in barley. Science. 2005:310:1031-4

52. Pourkheirandish M, Komatsuda T. The Importance of Barley Genetics and Domestication in a Global Perspective. Ann Bot. 2007;100(5):999-1008.

53. Laurie DA, Pratchett N, Bezant JH, Snape JW. RFLP mapping of five major genes and eight quantitative trait loci controlling flowering time in a winter × spring barley (Hordeum vulgare L.) cross. Genome. 1995;38:575-85.

54. Sameri M, Pourkheirandish M, Chen G, Tonooka T, Komatsuda T. Detection of photoperiod responsive and nonresponsive flowering time QTL in barley. Breeding Science. 2011;61(2):183-8.

55. Boyd W, Li CD, Grime C, Cakir M, Potipibool S, Kaveeta L, et al. Conventional and molecular genetic analysis of factors contributing to variation in the timing of heading among spring barley (Hordeum vulgare L.) genotypes grown over a mild winter growing season. Crop Past Sci. 2003;54:1277-1301.

56. Chang S-B, de Jong $\mathrm{H}$. Production of alien chromosome additions and their utility in plant genetics. Cytogenet Genome Res. 2005;109:335-43.

57. Cseh A, Kruppa K, Molnár I, Rakszegi M, Doležel J, Molnár-Láng M. Characterization of a new 4BS.7HL wheat-barley translocation line using GISH, FISH, and SSR markers and its effect on the $\beta$-glucan content of wheat. Genome. 2011:54:795-804

58. Cseh A, Türkösi E, King J, King I, Molnár-Láng M. Development of new winter wheat-winter barley 7BS.7HL Robertsonian translocation line. London: Plant Genomics Congress; 2015. pp. 30. Available online at http://www.globalengage.co.uk/ngs/posters15.pdf.

\section{Submit your next manuscript to BioMed Central and we will help you at every step:}

- We accept pre-submission inquiries

- Our selector tool helps you to find the most relevant journal

- We provide round the clock customer support

- Convenient online submission

- Thorough peer review

- Inclusion in PubMed and all major indexing services

- Maximum visibility for your research

Submit your manuscript at www.biomedcentral.com/submit 